\title{
The Polyuria-Polydipsia Syndrome: a diagnostic challenge
}

Nicole Nigro ${ }^{1}$, Mathis Grossmann ${ }^{3,4}$, Cherie Chiang ${ }^{4}$, Warrick J Inder ${ }^{1,2}$

${ }^{1}$ Department of Diabetes and Endocrinology, Princess Alexandra Hospital, Brisbane, Australia. ${ }^{2}$ Faculty of Medicine, University of Queensland, Brisbane, Australia.

${ }^{3}$ Department of Medicine, Austin Health, University of Melbourne, Melbourne, Australia.

${ }^{4}$ Department of Endocrinology, Austin Health, University of Melbourne, Melbourne, Australia.

\section{Word count abstract: 244}

Word count manuscript: 3666

\section{Correspondence}

Nicole Nigro

Princess Alexandra Hospital

Department of Diabetes and Endocrinology

Woolloongabba, Brisbane, QLD 4102, Australia.

Email: nicole.nigro@mater.uq.edu.au

\section{Acknowledgment:}

The Harmonisation of Dynamic Endocrine Tests Working Group of the Endocrine Society of Australia (ESA), Australasian Association of Clinical Biochemists (AACB) and the Royal College of Pathologists of Australasia (RCPA), including Rory Clifton Bligh, Penelope Coates, James Doery, Lim Ee Mun and Phoebe Stanford have reviewed and approved the water deprivation test protocol.

This is the author manuscript accepted for publication and has undergone full peer review but has not been through the copyediting, typesetting, pagination and proofreading process, which may lead to differences between this version and the Version of Record. Please cite this article as doi: $10.1111 / \mathrm{imj} .13627$

This article is protected by copyright. All rights reserved. 


\section{Conflict of interest statement:}

The authors reported no conflict of interest. No funding was obtained for this review.

This article is protected by copyright. All rights reserved. 


\section{The Polyuria-Polydipsia Syndrome: a diagnostic challenge}

\section{Introduction:}

Water homeostasis is mainly balanced by two regulating factors: the hormone arginine vasopressin (AVP), also known as antidiuretic hormone (ADH), and thirst. AVP is the prime determinant regulating total body water via free water excretion. AVP - a nine-amino-acid peptide - is derived from a 164 amino-acid precursor protein consisting of a signal peptide, AVP itself, neurophysin 2 and the c-terminal glycoprotein copeptin ${ }^{1}$. It is synthesized in magnocellular neurons located in two distinct parts of the hypothalamus, the supraoptic and paraventricular nuclei, and then stored in neurosecretory granules ${ }^{2}$ in the posterior pituitary until specific stimuli cause secretion of AVP ${ }^{2,3}$. The circulating concentration of AVP is directly related to serum osmolality and even an increase in serum osmolality as small as $1 \%$ can lead to AVP release from the posterior pituitary ${ }^{4}$. In healthy subjects, approximately 280 $\mathrm{mOsm} / \mathrm{kg}$ is considered the "osmotic threshold" for AVP release and a linear increase in the concentration of AVP with increased osmolality has been described (Figure 1) ${ }^{4,5}$. In addition to osmotic stimuli, AVP increases in response to stressors such as hypotension, sepsis, hypoglycaemia, exercise and nausea/vomiting ${ }^{6}$. There is evidence for a direct stimulatory effect of angiotensin II and inhibitory effects of cortisol and atrial natriuretic peptide ${ }^{6}$. AVP binds to vasopressin-2 receptors on the basal membrane of the renal collecting tubular cell, which leads to an increase in the tubular fluid permeability by installing aquaporin-2 water channels ${ }^{7}$. This in turn, given the higher intramedullary osmolality compared to that of tubular fluid, leads to water retention and urinary concentration.

The second main mechanism to preserve water homeostasis is thirst. As well as causing an increase in AVP, a rise in serum osmolality leads to an increase in thirst sensation, which promotes oral intake of water and maintenance of serum osmolality within the physiological range (Figure 1) ${ }^{5}$. The pathway through which thirst sensation occurs is not fully understood ${ }^{8}$ but data suggest that central osmoreceptors distinct from those regulating AVP production are involved ${ }^{9}$. These osmoreceptors are located in the hypothalamic region and several conditions arising from infiltrative, neoplastic, vascular, congenital and traumatic processes can be associated with abnormalities in thirst, leading to augmented or diminished fluid intake $^{10}$. 
Polyuria, defined as an excretion of abnormally large volumes of dilute urine (i.e. $>3 \mathrm{~L} / 24 \mathrm{~h}$ or $>40-50 \mathrm{ml} / \mathrm{kg} / 24 \mathrm{~h}$ ), can occur in various diseases ${ }^{11}$ which are summarized as the polyuriapolydipsia syndrome. The spectrum of the polyuria-polydipsia syndrome includes central and nephrogenic diabetes insipidus (DI) as well as primary polydipsia. Treatment approaches are different in these three conditions and therefore careful differentiation is crucial.

The purpose of this review is to detail the differential diagnoses of the polyuria-polydipsiasyndrome, the challenges in the diagnostic procedures, to present new possible approaches in the diagnostic algorithm such as plasma copeptin as a surrogate marker for AVP secretion ${ }^{12}$, 13 and provide a standardised method for the performance of a water deprivation test in Australia. This is part of the joint initiative by the Endocrine Society of Australia (ESA), the Australasian Association of Clinical Biochemists (AACB) and Royal College of Pathologists of Australasia (RCPA) of aiming to harmonise dynamic endocrine testing across the country. A comprehensive literature review was performed. The electronic search was performed using PubMed and including the following search terms "polyuria-polydipsia-syndrome" "diagnosis of diabetes insipidus, "central diabetes insipidus", "nephrogenic diabetes insipidus", "psychogenic OR primary polydipsia"; "water deprivation test"; "vasopressin" and "copeptin". In addition, a manual search of the reference lists of the articles found was performed.

\section{Differential diagnosis of the polyuria-polydipsia syndrome:}

The polyuria-polydipsia syndrome may arise from central DI, caused by insufficient secretion of AVP, nephrogenic DI resulting from resistance to AVP action in the kidneys and primary polydipsia, by which excessive water intake leads to physiologic suppression of AVP.

\section{Central diabetes insipidus}

Central or neurogenic DI is due to a deficiency of AVP production and/or secretion caused by a variety of acquired or congenital disorders. Clinical manifestations of acquired or congenital central DI are variable and range from mild to severe forms, depending on the degree of neuronal damage. Usually, before patients manifest polyuria or polydipsia, $80 \%$ to $90 \%$ of the magnocellular neurons in the hypothalamus need to be destroyed ${ }^{14}$. In magnetic 
resonance imaging (MRI), the posterior pituitary shows a hyperintense signal on sagittal T1weighted imaging in healthy patients (the posterior pituitary "bright spot") and the absence of this hyperintensity is used as a non-specific hallmark of central DI ${ }^{15}$.

Aetiologies for acquired central DI include pituitary surgery, some types of central nervous system tumours, trauma, haemorrhage, autoimmune and granulomatous disease, whereas genetic mutations of the AVP gene are much less common (see Table 1). The most frequently encountered entity of acquired central DI is after transsphenoidal surgery. Transient central DI is observed in $16-34 \%$ of patients recovering from sellar region operations and $2-10 \%$ develop permanent central DI ${ }^{16}$. A variety of central nervous system tumours has been shown to be associated with central DI. Especially in children and young adults, tumours involving the hypothalamus (i.e. craniopharyngioma, germ cell tumours) and central nervous system malformations are a common cause of central DI, accounting for approximately one third of the acquired cases ${ }^{17}$. By contrast, although case reports have been published, pituitary adenomas very rarely present with central DI, even when complete anterior pituitary insufficiency is present ${ }^{18}$. In about $25 \%$ of the patients with central DI, no clinical evidence of a related disease can be linked and no abnormality is found on neuroimaging (classified as idiopathic central DI) ${ }^{17}$. However, in one third of patients with apparently idiopathic central DI, AVP-secreting cell autoantibodies have been demonstrated, suggesting an underlying autoimmune basis ${ }^{19}$. Autoimmune destruction of the posterior pituitary often presents with pituitary stalk thickening and enlargement of the posterior pituitary in imaging studies ${ }^{19}$.

Diabetes insipidus occurring during pregnancy is often transient and develops due to accelerated degradation of AVP by increased activity of placental vasopressinase ${ }^{20}$. Congenital forms of central DI are uncommon, mostly inherited in an autosomal-dominant fashion and account for $1-5 \%$ of all causes of central DI ${ }^{21}$. So far, several different mutations located in the coding region of the AVP precursor gene have been reported ${ }^{22}$. These mutations lead to an abnormal precursor protein, which accumulates within the neuron. It appears that the slow progressive cell apoptosis causes the AVP deficiency. Hence, congenital central DI typically develops months to years after birth ${ }^{23,24}$. Rarely, central DI is inherited in an autosomal recessive manner and is caused by mutations in the WSF1 gene encoding wolframin. The protein wolframin is involved in pancreatic beta cell proliferation, intracellular protein processing and calcium homeostasis. Its deficiency produces a wide 
spectrum of endocrine and central nervous system disorders, such as central DI, diabetes mellitus, optic atrophy and deafness (DIDMOAD) ${ }^{22}$.

Nephrogenic diabetes insipidus

In patients with nephrogenic DI the renal action of AVP is decreased because of an acquired or genetic defect (Table 1). The clinical presentation is similar to central DI except that basal plasma AVP is elevated, similar to other endocrine syndromes of hormone resistance. Where nephrogenic DI is present, up to $95 \%$ of adults have the acquired form, with lithium treatment being the principal cause. Acquired nephrogenic DI can also be due to other drugs, such as antifungal agents (amphotericin B), antibiotics (ofloxacin, demeclocycline), dexamethasone, dopamine, ifosfamide, orlistat and cisplatin ${ }^{25}$. Typically transient nephrogenic DI can occur in patients with acute or chronic renal failure, hypokalaemia, hypercalcaemia and after relief of obstructive nephropathy ${ }^{25}$.

Congenital nephrogenic DI is less common and in about $90 \%$ of cases, congenital nephrogenic DI is due to mutations in the AVP-receptor 2 gene and mostly inherited in an Xlinked recessive manner. In a few cases, autosomal recessive or dominant mutations in the aquaporin-2 gene have been described ${ }^{26}$. Consequently, most of these patients are male and the clinical presentation includes hypernatraemic dehydration combined with dilute urine as well as failure to thrive ${ }^{26}$.

\section{Primary Polydipsia}

Primary polydipsia is caused by excessive fluid intake which results in a decrease in serum osmolality and consequently in an inhibition of AVP and hypotonic polyuria. Primary polydipsia was first described in patients with schizophrenia and was therefore named psychogenic polydipsia ${ }^{27}$. However, psychiatric diseases other than schizophrenia such as anxiety disorders, depression and addictive disorders have been linked with this disease ${ }^{27}$. Another form of primary polydipsia is dipsogenic polydipsia, which occurs mostly in healthy people. This might be explained by a disturbed thirst sensation ${ }^{27}$ and a lower osmotic limit of thirst sensitivity below the osmotic threshold for AVP secretion ${ }^{28}$.

\section{Diagnosis:}


Accurate differentiation of the underlying cause of the polyuria-polydipsia-syndrome is important because treatment approaches differ considerably.

Symptoms or clinical findings such as headache, visual impairment, hypopituitarism, head trauma, medications, past medical history, pregnancy, drinking habits and onset of polyuria are important to elicit. Once polyuria is confirmed (i.e. $>3 \mathrm{~L} / 24 \mathrm{~h}$ or $>40-50 \mathrm{ml} / \mathrm{kg} / 24 \mathrm{~h}$ ), further investigations are necessary. The first step in evaluating patients with polyuriapolydipsia syndrome is ruling out other aetiologies, which are not primarily caused by impaired AVP secretion or action, such as hyperglycaemia or hypercalcaemia. Aetiologies such as central DI, nephrogenic DI and primary polydipsia have to be considered next.

Urine osmolality that is greater than a paired serum osmolality indicates water conservation is present. In patients with milder polyuria who can tolerate overnight water deprivation, a urine osmolality above $800 \mathrm{mOsm} / \mathrm{kg}$ indicates normal AVP function. All other patients should undergo further testing.

Currently, the classic water deprivation test followed by the injection of desmopressin (DDAVP) ${ }^{29}, 30$ is the routinely used method for the confirmation and subsequent differentiation of the various entities of the polyuria-polydipsia syndrome. AVP activity is indirectly evaluated via the urine osmolality achieved after prolonged fluid deprivation. Once maximal urine concentration is reached, AVP deficiency or resistance is tested by the renal response post-administration of DDAVP.

The first to describe a standardised test protocol was Miller in the early 1970's ${ }^{29}$. In this small study, patients with polyuria-polydipsia syndrome and healthy volunteers underwent prolonged fluid deprivation. Once urine osmolality showed a plateau between two consecutive urine collections, exogenous vasopressin was administered. Following 8 hours of fluid deprivation, healthy volunteers $(n=10)$ without polyuria or polydipsia showed an adequate rise in urine osmolality, defined as $>800 \mathrm{mOsm} / \mathrm{kg}$, which did not rise further by more than 5\% after vasopressin injection (see Figures 2 and 3). The various differential diagnoses of the polyuria-polydipsia syndrome showed different urine osmolality patterns: 19 patients with complete central DI were not able to concentrate the urine osmolality above their plasma osmolality during dehydration, but demonstrated an increase of $>50 \%$ in urine osmolality after administration of vasopressin. Similarly, two patients with complete 
nephrogenic DI could not increase the urine osmolality above the plasma osmolality, and showed a rise of $<50 \%$ after injection of vasopressin. Conversely, patients with partial central DI $(n=13)$ were capable of concentrating the urine above the plasma osmolality during water deprivation and had an increase in urine osmolality of $>9 \%$ after vasopressin. Seven patients with primary polydipsia showed a urine concentrating capacity during water deprivation that was similar to patients with partial central DI. However, patients with primary polydipsia showed only a slight increase in urine osmolality after administration of vasopressin between 2 and 13\%. Reanalysing Miller's original data by receiver-operator characteristic (ROC) curve analysis, the optimal cut-off point differentiating between partial central DI and primary polydipsia is an increase in urinary osmolality of $>10 \%$, which gives a sensitivity of $93 \%$ and specificity of $83 \%$. It is noteworthy though that the single patient with primary polydipsia whose urine osmolality increased by more than $10 \%$, had a urine osmolality at the end of the period of water deprivation of $>800 \mathrm{mosmol} / \mathrm{kg}$ and therefore would have been correctly classified as primary polydipsia on that basis.

Currently, in many endocrine centres, the classic water deprivation test is utilised for the differentiation of the polyuria-polydipsia syndrome. However, in clinical practice this test has several limitations. First, the dehydration period is uncomfortable for many patients and the test is often discontinued before maximal urine osmolality is reached. Second, long standing polyuria may produce washout of the renal medullary concentration gradient, leading to diminished maximal urine concentrating ability regardless of the initial cause and causing relative AVP resistance. This process is due to a down regulation of aquaporin-2 synthesis limiting the renal response to maximal AVP secretion ${ }^{31}$. This can result in a diminished increase in urine osmolality after the DDAVP challenge in patients with the polyuriapolydipsia syndrome, therefore decreasing the diagnostic utility of the water deprivation test. Additionally, many patients with partial central DI or nephrogenic DI still have a limited capacity to secrete or to respond to AVP. Therefore, an absolute distinction between primary polydipsia, partial central DI and partial nephrogenic DI is often not possible ${ }^{29,32}$.

In the early 1980s direct measurement of AVP was proposed to improve diagnostic utility of the classic water deprivation test. Zerbe et al. ${ }^{33}$ investigated whether AVP measurements added to a water deprivation test improves the differential diagnosis of polyuria-polydipsia syndrome. The water deprivation test alone was not reliable, especially for distinguishing partial central DI and primary polydipsia, whereas vasopressin measurement revealed that 
two out of six patients with partial central DI had normal vasopressin secretion; one was found to have primary polydipsia, and the other nephrogenic DI. Moreover, three of 10 patients diagnosed as having primary polydipsia by the water deprivation test had clear evidence of partial vasopressin deficiency by the direct assay. Similar results were obtained in another study ${ }^{34}$, where measurement of plasma AVP during osmotic stimulation with hypertonic 5\% saline infusion and indirect assessment of antidiuretic activity by urine osmolality measurements during standard water deprivation test were compared. All patients with primary polydipsia were identified with both tests, however, two of four patients with undetectable plasma AVP concentrations were categorized as partial central DI or nephrogenic DI according to their urine results during the water deprivation test. However, both studies had the limitation of a missing diagnostic "gold-standard" test, which makes it difficult to interpret these results. Additionally, there are no clearly defined normative ranges for AVP concentrations appropriate for a given serum osmolality. In the above studies AVP concentrations were interpreted according to a small study involving healthy volunteers, which showed a linear AVP rise with increasing serum osmolality ${ }^{4}$. However, recent data in a larger cohort of healthy volunteers showed that the association between AVP and serum osmolality is less close and clearly nonlinear ${ }^{35}$. Consequently, this raises some concerns on the reliability of the interpretation of AVP concentrations. Furthermore, AVP is a labile peptide with short half-life of six minutes and mostly platelet bound ${ }^{36}$. Collection needs to be on ice and processed rapidly to avoid falsely low results from AVP breakdown. Conversely, platelet rich plasma samples result in falsely high AVP values ${ }^{37}$. Because of these methodical difficulties, AVP measurement has not been implemented as a routinely used parameter for the differential diagnosis of the polyuria-polydipsia syndrome.

Further investigation to improve the differential diagnosis of the polyuria-polydipsia syndrome has been undertaken in the past few years. In 2011, Fenske et al. assessed the diagnostic performance of the classic water deprivation test and its combination with direct AVP measurements in 50 patients with polyuria-polydipsia syndrome ${ }^{35}$. In line with already discussed limitations, their investigation revealed a weak diagnostic performance of the classic water deprivation test with an overall diagnostic accuracy of $70 \%$ and only $41 \%$ were diagnosed correctly in the subgroup of patients with primary polydipsia. AVP measurement did not improve the diagnostic accuracy and just 38\% of the patients were diagnosed correctly. In the same study, circulating copeptin, the c-terminal portion of the precursor peptide of AVP was proposed as an alternative method to differentiate between various 
differential diagnoses of the polyuria-polydipsia syndrome. Copeptin is produced in equimolar amounts to AVP, has a similar half-life ${ }^{12}$ and mirrors circulating AVP concentrations ${ }^{13}$. However, copeptin, as the larger $37 \mathrm{kDa}$ glycoprotein, is stable in plasma and serum, can be easily determined using automated chemiluminescence immunoassay rather than the more cumbersome radioimmunoassay and is therefore potentially superior to AVP measurement ${ }^{12}$. In Fenske's study of 50 patients with polyuria-polydipsia syndrome and 20 healthy controls, a single copeptin measurement after overnight water deprivation $>20.0 \mathrm{pmol} / \mathrm{L}$ was shown to reliably detect patients with nephrogenic DI with a sensitivity and specificity of $100 \%$, although only 2 patients in that study were diagnosed with nephrogenic DI. Conversely, all nine patients with complete central DI had baseline copeptin concentrations $<2.6 \mathrm{pmol} / \mathrm{L}$. With respect to the difficult differential diagnosis between patients with primary polydipsia and partial central DI, a baseline copeptin value $>3 \mathrm{pmol} / \mathrm{L}$ had a sensitivity and specificity of $82 \%$ and $92 \%$ to diagnose primary polydipsia. In contrast, a copeptin value e $5.0 \mathrm{pmol} / \mathrm{L}$ after the water deprivation revealed a sensitivity and specificity of $96 \%$ and $81 \%$ for the diagnosis of primary polydipsia. The ratio between the change in (delta) plasma copeptin and serum sodium values at the end of dehydration increased the diagnostic accuracy significantly (94\%) with a specificity of $100 \%$ and sensitivity of $86 \%$ to separate primary polydipsia from partial central DI ${ }^{35}$.

The diagnostic potential of copeptin has been studied in another prospective study including 55 patients with polyuria-polydipsia syndrome (27 with central DI, 10 with nephrogenic DI and 18 with primary polydipsia) who underwent a standardised water deprivation test combined with $3 \%$ saline infusion and serial copeptin and AVP measurements ${ }^{38}$. The major strength of this study compared to that of Fenske was that all patients had a maximal stimulus for AVP secretion due to a sufficient increase in serum osmolality (i.e. serum sodium values $>147 \mathrm{mmol} / \mathrm{L}$ ). Data showed that copeptin measurements were superior to AVP for the differential diagnosis of polyuria-polydipsia syndrome. A single baseline copeptin measurement e $21.4 \mathrm{pmol} / \mathrm{L}$ without prior water deprivation showed an excellent diagnostic accuracy (specificity/sensitivity of 100\%) to diagnose partial or complete nephrogenic DI in this cohort. Furthermore, copeptin concentrations e5.0 pmol/L after maximal osmotic stimulation (i.e. serum sodium value $>147 \mathrm{mmol} / \mathrm{L}$ ) differentiated between patients with primary polydipsia and partial central DI with a specificity of $94.0 \%$ and a sensitivity of $94.4 \%$. 
Given that stress can stimulate AVP and hence copeptin secretion, copeptin has also been evaluated as a marker for disease severity and been reported to correlate with disease severity in patients with sepsis, ischaemic stroke or heart failure ${ }^{39-41}$. Therefore, in acutely ill patients copeptin might be a misleading marker of water balance and should be interpreted with caution.

Another biomarker that has been evaluated for the differential diagnosis of the polyuriapolydipsia syndrome is apelin, a neuro-vasoactive peptide which is involved in body fluid homeostasis and regulated in the opposite direction to AVP. A recent study investigated plasma apelin and plasma apelin:copeptin ratio in 41 patients with polyuria-polydipsia syndrome and 113 healthy volunteers ${ }^{42}$. Apelin concentrations were highest in patients with complete nephrogenic DI and lower in patients with primary polydipsia or complete central DI as compared to healthy volunteers. The apelin:copeptin ratio in healthy volunteers was similar to those with primary polydipsia. In contrast, the apelin:copeptin ratio in patients with complete central and nephrogenic DI was significantly lower compared to healthy volunteers. So far, this was a proof of concept study and patients with partial central and nephrogenic DI were not considered. Therefore, these results need to be evaluated in larger studies with milder forms of these conditions.

Considering these promising studies, with the caveat that they are based on a relatively small number of patients and require validation in larger cohorts, a classic water deprivation test combined with copeptin measurement may become the new standard diagnostic procedure for the differential diagnosis of the polyuria-polydipsia syndrome. Currently, copeptin measurement is not routinely available in Australia; however, some laboratories are in the process of developing this. Until copeptin is available and its utility confirmed we suggest performing a classic water deprivation test for the differential diagnosis of the polyuriapolydipsia syndrome according to a standardised protocol (see Table 2). Importantly, to strengthen the value of the water deprivation test, patients must reach a maximal plateau in urine concentration (i.e. $<30 \mathrm{mOsm} / \mathrm{kg}$ increase in urine osmolality between two consecutive measurements). This might take up to 18 hours and is one of the main limiting factors ${ }^{29}$. While the original Miller study showed some overlap, the key differentiating feature between partial central DI and primary polydipsia is the additional increase in urine osmolality which occurs in central DI after DDAVP administration, which should be absent in primary 
polydipsia patients provided they have reached their maximal urine concentrating ability prior to the DDAVP.

When copeptin measurement becomes available, we suggest as the primary step a single basal measurement. Local reference intervals need to be established, but published data to this point indicate copeptin concentrations e $21.4 \mathrm{pmol} / \mathrm{L}$ with or without prior fluid deprivation are highly suggestive of partial or complete nephrogenic DI. If copeptin concentrations are $<2.6 \mathrm{pmol} / \mathrm{L}$ after overnight fluid deprivation (i.e. minimum of 8 hours), a diagnosis of central DI is probable. In all other patients, we recommend performing the classic water deprivation test in combination with copeptin measurement. Since copeptin has only been validated in a small patient cohort, the proposed cut-off values have to be prospectively validated in larger cohorts (see Figure 4).

\section{Conclusion:}

While severe DI is usually straightforward to diagnose in the appropriate clinical context, such as after pituitary surgery, milder forms can be difficult to differentiate from primary polydipsia. After a careful assessment of symptoms, medication and concomitant medical history, further evaluation should be performed. So far, despite several limitations, the classical indirect water deprivation test is still the best diagnostic procedure for the differential diagnosis of the polyuria-polydipsia syndrome. However, promising results show that measurement of copeptin, the c-terminal portion of the precursor peptide of AVP, and perhaps additional peptides such as apelin could substantially improve the diagnostic accuracy of the water deprivation test in patients with polyuria-polydipsia syndrome, allowing tailoring treatment of these conditions more precisely. 


\section{References}

1 Land H, Schutz G, Schmale H, Richter D. Nucleotide sequence of cloned cDNA encoding bovine arginine vasopressin-neurophysin II precursor. Nature. 1982; 295: 299-303.

2 Robertson GL. Physiology of ADH secretion. Kidney Int Suppl. 1987; 21: S20-6.

3 Schmale H, Heinsohn S, Richter D. Structural organization of the rat gene for the arginine vasopressin-neurophysin precursor. EMBO J. 1983; 2: 763-7.

4 Baylis PH, Robertson GL. Plasma vasopressin response to hypertonic saline infusion to assess posterior pituitary function. $J R$ Soc Med. 1980; 73: 255-60.

$5 \quad$ Verbalis JG. Disorders of body water homeostasis. Best Pract Res Clin Endocrinol Metab. 2003; 17: 471-503.

6 Ball SG. Vasopressin and disorders of water balance: the physiology and pathophysiology of vasopressin. Ann Clin Biochem. 2007; 44: 417-31.

7 Juul KV, Bichet DG, Nielsen S, Norgaard JP. The physiological and pathophysiological functions of renal and extrarenal vasopressin V2 receptors. Am J Physiol Renal Physiol. 2014; 306: F931-40.

8 Zimmerman EA, Ma LY, Nilaver G. Anatomical basis of thirst and vasopressin secretion. Kidney Int Suppl. 1987; 21: S14-9.

9 Thrasher TN, Keil LC, Ramsay DJ. Lesions of the organum vasculosum of the lamina terminalis (OVLT) attenuate osmotically-induced drinking and vasopressin secretion in the dog. Endocrinology. 1982; 110: 1837-9.

10 Baylis PH, Thompson CJ. Osmoregulation of vasopressin secretion and thirst in health and disease. Clin Endocrinol (Oxf). 1988; 29: 549-76.

11 Robertson GL. Antidiuretic hormone. Normal and disordered function. Endocrinol Metab Clin North Am. 2001; 30: 671-94, vii.

12 Morgenthaler NG, Struck J, Alonso C, Bergmann A. Assay for the measurement of copeptin, a stable peptide derived from the precursor of vasopressin. Clin Chem. 2006; 52: 112-9.

13 Szinnai G, Morgenthaler NG, Berneis K, Struck J, Muller B, Keller U, et al. Changes in plasma copeptin, the c-terminal portion of arginine vasopressin during water deprivation and excess in healthy subjects. J Clin Endocrinol Metab. 2007; 92: 3973-8.

14 Heinbecker P, White HL. The Role of the Pituitary Gland in Water Balance. Ann Surg. 1939; 110: $1037-49$.

15 Maghnie M, Sommaruga MG, Beluffi G, Severi F. Role of MR imaging in the evaluation of the functional status of the posterior pituitary gland: the view of a pediatric endocrinologist. AJNR Am J Neuroradiol. 1993; 14: 1443-5.

16 Nemergut EC, Zuo Z, Jane JA, Jr., Laws ER, Jr. Predictors of diabetes insipidus after transsphenoidal surgery: a review of 881 patients. J Neurosurg. 2005; 103: 448-54.

17 Maghnie M, Cosi G, Genovese E, Manca-Bitti ML, Cohen A, Zecca S, et al. Central diabetes insipidus in children and young adults. $N$ Engl J Med. 2000; 343: 998-1007.

18 Arima H, Wakabayashi T, Nagatani T, Fujii M, Hirakawa A, Murase T, et al. Adipsia increases risk of death in patients with central diabetes insipidus. Endocr J. 2014; 61: 143-8.

19 Pivonello R, De Bellis A, Faggiano A, Di Salle F, Petretta M, Di Somma C, et al. Central diabetes insipidus and autoimmunity: relationship between the occurrence of antibodies to arginine vasopressin-secreting cells and clinical, immunological, and radiological features in a large cohort of patients with central diabetes insipidus of known and unknown etiology. J Clin Endocrinol Metab. 2003; 88: 1629-36.

20 Ananthakrishnan S. Diabetes insipidus during pregnancy. Best Pract Res Clin Endocrinol Metab. 2016; 30: 305-15.

21 Babey M, Kopp P, Robertson GL. Familial forms of diabetes insipidus: clinical and molecular characteristics. Nat Rev Endocrinol. 2011; 7: 701-14.

22 Rutishauser J, Spiess M, Kopp P. Genetic forms of neurohypophyseal diabetes insipidus. Best Pract Res Clin Endocrinol Metab. 2016; 30: 249-62.

23 Gagliardi PC, Bernasconi S, Repaske DR. Autosomal dominant neurohypophyseal diabetes insipidus associated with a missense mutation encoding Gly23-->Val in neurophysin II. $J$ Clin Endocrinol Metab. 1997; 82: 3643-6. 
24 Green JR, Buchan GC, Alvord EC, Jr., Swanson AG. Heredtary and idiopathic types of diabetes insipidus. Brain. 1967; 90: 707-14.

25 Moeller HB, Rittig S, Fenton RA. Nephrogenic diabetes insipidus: essential insights into the molecular background and potential therapies for treatment. Endocr Rev. 2013; 34: 278-301.

26 Bichet DG, Bockenhauer D. Genetic forms of nephrogenic diabetes insipidus (NDI):

Vasopressin receptor defect (X-linked) and aquaporin defect (autosomal recessive and dominant).

Best Pract Res Clin Endocrinol Metab. 2016; 30: 263-76.

27 Dundas B, Harris M, Narasimhan M. Psychogenic polydipsia review: etiology, differential, and treatment. Curr Psychiatry Rep. 2007; 9: 236-41.

28 Thompson C, Edwards C, Baylis P. Osmotic and non-osmotic regulation of thirst and vasopressin secretion in patients with compulsive water drinking. Clinical endocrinology. 1991; 35: 221-28.

29 Miller M, Dalakos T, Moses AM, Fellerman H, Streeten DH. Recognition of partial defects in antidiuretic hormone secretion. Ann Intern Med. 1970; 73: 721-9.

30 Dashe AM, Cramm RE, Crist CA, Habener JF, Solomon DH. A water deprivation test for the differential diagnosis of polyuria. JAMA. 1963; 185: 699-703.

31 Cadnapaphornchai MA, Summer SN, Falk S, Thurman JM, Knepper MA, Schrier RW. Effect of primary polydipsia on aquaporin and sodium transporter abundance. Am J Physiol Renal Physiol. 2003; 285: F965-71.

32 Robertson GL. Diabetes insipidus. Endocrinol Metab Clin North Am. 1995; 24: 549-72.

33 Zerbe RL, Robertson GL. A comparison of plasma vasopressin measurements with a standard indirect test in the differential diagnosis of polyuria. N Engl J Med. 1981; 305: 1539-46.

34 Milles JJ, Spruce B, Baylis PH. A comparison of diagnostic methods to differentiate diabetes insipidus from primary polyuria: a review of 21 patients. Acta Endocrinol (Copenh). 1983; 104: 4106.

35 Fenske W, Quinkler M, Lorenz D, Zopf K, Haagen U, Papassotiriou J, et al. Copeptin in the differential diagnosis of the polydipsia-polyuria syndrome--revisiting the direct and indirect water deprivation tests. J Clin Endocrinol Metab. 2011; 96: 1506-15.

36 Fabian M, Forsling ML, Jones JJ, Pryor JS. The clearance and antidiuretic potency of neurohypophysial hormones in man, and their plasma binding and stability. $J$ Physiol. 1969; 204: 65368.

37 Leng G, Sabatier N. Measuring Oxytocin and Vasopressin: Bioassays, Immunoassays and Random Numbers. J Neuroendocrinol. 2016; 28.

38 Timper K, Fenske W, Kuhn F, Frech N, Arici B, Rutishauser J, et al. Diagnostic Accuracy of Copeptin in the Differential Diagnosis of the Polyuria-polydipsia Syndrome: A Prospective Multicenter Study. J Clin Endocrinol Metab. 2015; 100: 2268-74.

39 Katan M, Fluri F, Morgenthaler NG, Schuetz P, Zweifel C, Bingisser R, et al. Copeptin: a novel, independent prognostic marker in patients with ischemic stroke. Ann Neurol. 2009; 66: 799808.

40 Maisel A, Xue Y, Shah K, Mueller C, Nowak R, Peacock WF, et al. Increased 90-day mortality in patients with acute heart failure with elevated copeptin: secondary results from the Biomarkers in Acute Heart Failure (BACH) study. Circ Heart Fail. 2011; 4: 613-20.

41 Morgenthaler NG, Muller B, Struck J, Bergmann A, Redl H, Christ-Crain M. Copeptin, a stable peptide of the arginine vasopressin precursor, is elevated in hemorrhagic and septic shock. Shock. 2007; 28: 219-26.

42 Urwyler SA, Timper K, Fenske W, de Mota N, Blanchard A, Kuhn F, et al. Plasma Apelin Concentrations in Patients With Polyuria-Polydipsia Syndrome. J Clin Endocrinol Metab. 2016; 101: 1917-23. 


\section{Figure legend}

Figure 1: Osmotic stimulation of vasopressin release. Schematic representation of normal physiological relationships between plasma osmolality, plasma AVP concentrations, urine osmolality and urine volume in man

Figure 2: Maximum urinary osmolality after dehydration. Data from Miller et $\mathrm{al}^{29}$

Figure 3: Change in urinary osmolality after vasopressin injection. Data from Miller et al ${ }^{29}$

Figure 4: Proposed diagnostic algorithm for the differential diagnosis of the polyuriapolydipsia syndrome

This article is protected by copyright. All rights reserved. 
Table 1: Aetiologies of central and nephrogenic diabetes insipidus

\begin{tabular}{|c|c|}
\hline Various aetiologies of central diabetes insipidus & Various aetiologies of nephrogenic diabetes insipidus \\
\hline $\begin{array}{l}\text { Acquired: } \\
\text { - Pituitary surgery, head trauma (deceleration) } \\
\text { - Tumours comprising the hypothalamus or posterior pituitary (e.g. } \\
\text { craniopharyngioma, germ cell tumours, metastases, pituitary adenomas), } \\
\text { central nervous system malformations (e.g. hydrocephalus, } \\
\text { ventricular/suprasellar cyst, Rathke's cleft cyst) } \\
\text { - Vascular (i.e. ischaemia, haemorrhage (Sheehan syndrome), thrombosis) } \\
\text { - Idiopathic } \\
\text { - Autoimmune or inflammatory diseases (i.e. lymphocytic } \\
\text { infundibuloneurohypophysitis, lymphocytic hypophysitis), granulomatous } \\
\text { (i.e. histiocytosis, sarcoidosis), infectious (i.e. toxoplasmosis, HIV, } \\
\text { meningitis, encephalitis) }\end{array}$ & $\begin{array}{l}\text { Acquired: } \\
\text { - Drug-induced (i.e. lithium, amphotericin B, } \\
\text { demeclocycline, dexamethasone, dopamine, ifosfamide, } \\
\text { ofloxacin, orlistat and cisplatin, etc.) } \\
\text { - } \text { Kidney disorders (i.e. acute and chronic kidney failure, } \\
\text { sarcoidosis, amyloidosis, obstructive nephropathy } \\
\text { - Hypercalcaemia and hypokalaemia } \\
\text { Congenital: } \\
\text { - AVP- receptor } 2 \text { gene mutations (inherited mostly X- } \\
\text { linked) } \\
\text { Aquaporin } 2 \text { gene mutations (inherited autosomal } \\
\text { recessive) }\end{array}$ \\
\hline $\begin{array}{l}\text { Congenital: } \\
\text { - } \\
\text { AVP precursor gene mutations } \\
\text { - Wolfram Syndrome (ㅁiabetes Insipidus, Diabetes Mellitus, Opptic } \underline{\text { Atrophy, }} \\
\quad \text { and Deafness, DIDMOAD) }\end{array}$ & \\
\hline $\begin{array}{l}\text { Gestational diabetes insipidus: } \\
\text { - Exacerbation of central or nephrogenic diabetes insipidus } \\
\text { - Increased degradation of AVP by placental vasopressinase }\end{array}$ & \\
\hline
\end{tabular}

This article is protected by copyright. All rights reserved. 
Table 2: Protocol for inpatient water deprivation test

\section{PATIENT PREPARATION:}

1. Document polyuria (i.e. $>3 \mathrm{~L} / 24$ hours or $40-50 \mathrm{ml} / \mathrm{kg} / 24$ hours)

2. Exclude other reasons for polyuria such as hyperglycaemia and hypercalcaemia

3. Check renal function and electrolytes and pituitary function including fT4, TSH and basal early morning cortisol

4. Check complete electrolytes and serum osmolality, copeptin (if available) and urine osmolality (i.e. $2^{\text {nd }}$ urine sample after one hour) after overnight water deprivation ( $>8$ hours).

If urine osmolality $>800 \mathrm{mOsm} / \mathrm{kg}^{\S}$ no further testing is required. In all other cases a classic water deprivation test is indicated

If copeptin $<2.6 \mathrm{pmol} / \mathrm{L}$ after overnight fluid deprivation diagnosis of central diabetes insipidus is suggestive

If copeptin e21.4pmol/L without prior water deprivation the diagnosis of nephrogenic diabetes insipidus is likely and no further testing may be necessary

5. Patients should refrain from tobacco, alcohol and caffeine 24 hours prior to test.

6. Stop DDAVP 24 hours before water deprivation test

\section{PROTOCOL FOR WATER DEPRIVATION TEST:}

1. Start water deprivation at $8 \mathrm{pm}$ for mild polyuria (i.e. 3-5 L/24h), at $12 \mathrm{am}$ for moderate polyuria (i.e. 5$7 \mathrm{~L} / 24 \mathrm{~h}$ ) and at $8 \mathrm{am}$ for severe polyuria (i.e. $>7 \mathrm{~L} / 24 \mathrm{~h}$ )*

2. Before starting water deprivation, take baseline weight, blood pressure and pulse, baseline blood test for serum osmolality, electrolytes, renal function, copeptin (if available) plus baseline urine osmolality and urine sodium

3. Repeat weight, blood pressure, pulse, urine osmolality hourly from 8am onwards

4. Repeat blood test every 4 hours $\uparrow$ (i.e. $8 \mathrm{am}, 12 \mathrm{pm}$ and $4 \mathrm{pm}$ ) and at termination of test immediately prior to injection of DDAVP

5. Duration of water deprivation period will vary for different patients. Indication for termination of water deprivation are the following:

Urine osmolality plateaus (i.e. $<30 \mathrm{mOsm} / \mathrm{kg}$ increase between two consecutive hourly

measurements). This indicates maximal urinary concentrating ability

- Weight loss of more than 3\% of baseline weight

- Serum sodium levels $>150 \mathrm{mmol} / \mathrm{L}$

- Urine osmolality $>800 \mathrm{mOsm} / \mathrm{kg}$

6. Intravenous injection of $2 \mu \mathrm{g}$ DDAVP

- not required if urine osmolality $>800 \mathrm{mOsmol} / \mathrm{kg}-\mathrm{DI}$ excluded

7. 1 hour after DDAVP administration: repeat blood test with serum osmolality and electrolytes plus 
repeat urine osmolality and urine sodium

\section{INTERPRETATION: (see also Figure 2-4)}

- Nephrogenic diabetes insipidus: urine osmolality after water deprivation $<300 \mathrm{mOsm} / \mathrm{kg}$, rise of urine osmolality after DDAVP $<50 \%$, baseline copeptin e $21.4 \mathrm{pmol} / \mathrm{L}$ without water deprivation

- Complete central diabetes insipidus: urine osmolality after water deprivation $<300 \mathrm{mOsm} / \mathrm{kg}$, rise of urine osmolality after DDAVP $>50 \%$, copeptin $<2.6 \mathrm{pmol} / \mathrm{L}$ after 8 hours water deprivation

- Partial central diabetes insipidus: urine osmolality after water deprivation 300-800 mOsm/kg, rise of urine osmolality after DDAVP $10-50 \%$, copeptin $<5.0 \mathrm{pmol} / \mathrm{L}$ after water deprivation

Primary polydipsia: urine osmolality after water deprivation $300-800 \mathrm{mOsm} / \mathrm{kg}$ or $>800$ $\mathrm{mOsm} / \mathrm{kg}$, rise of urine osmolality after DDAVP $<10 \%$, copeptin e $5.0 \mathrm{pmol} / \mathrm{L}$ after water deprivation

$\S$ Maximal urine osmolality $1200 \mathrm{mOsm} / \mathrm{kg}$. Depending on age and impaired renal function urine osmolality of $600 \mathrm{mOsm} / \mathrm{kg}$ can be acceptable depending on clinical judgment

* A more precise estimate of predicted time to achieve 3\% weight loss can be obtained using the formula:

Hourly weight loss $=$ urine volume $/ 24$. Time $(\mathrm{h})=0.03$ x weight $\times 24 / 24 \mathrm{~h}$ urine volume $(\mathrm{L})$.

e.g. $70 \mathrm{~kg}$ man with $24 \mathrm{~h}$ urine volume of $6 \mathrm{~L}: 0.03 \times 70 \times 24 / 6=8.4 \mathrm{~h}$

$\dagger$ In the setting of ongoing severe polyuria, more frequent checks of serum osmolality, electrolytes and renal function may be required according to the treating physician 


\section{Figure 1:}

Osmotic stimulation of vasopressin release. Schematic representation of normal physiological relationships between plasma osmolality, plasma AVP concentrations, urine osmolality and urine volume in man. Reproduced with permission from Elsevier Copyright (C) 2003 Verbalis JG. Disorders of body water homeostasis. Best Practice \&Research. Clinical Endocrinology \& Metabolism 200317 471-503 (5).

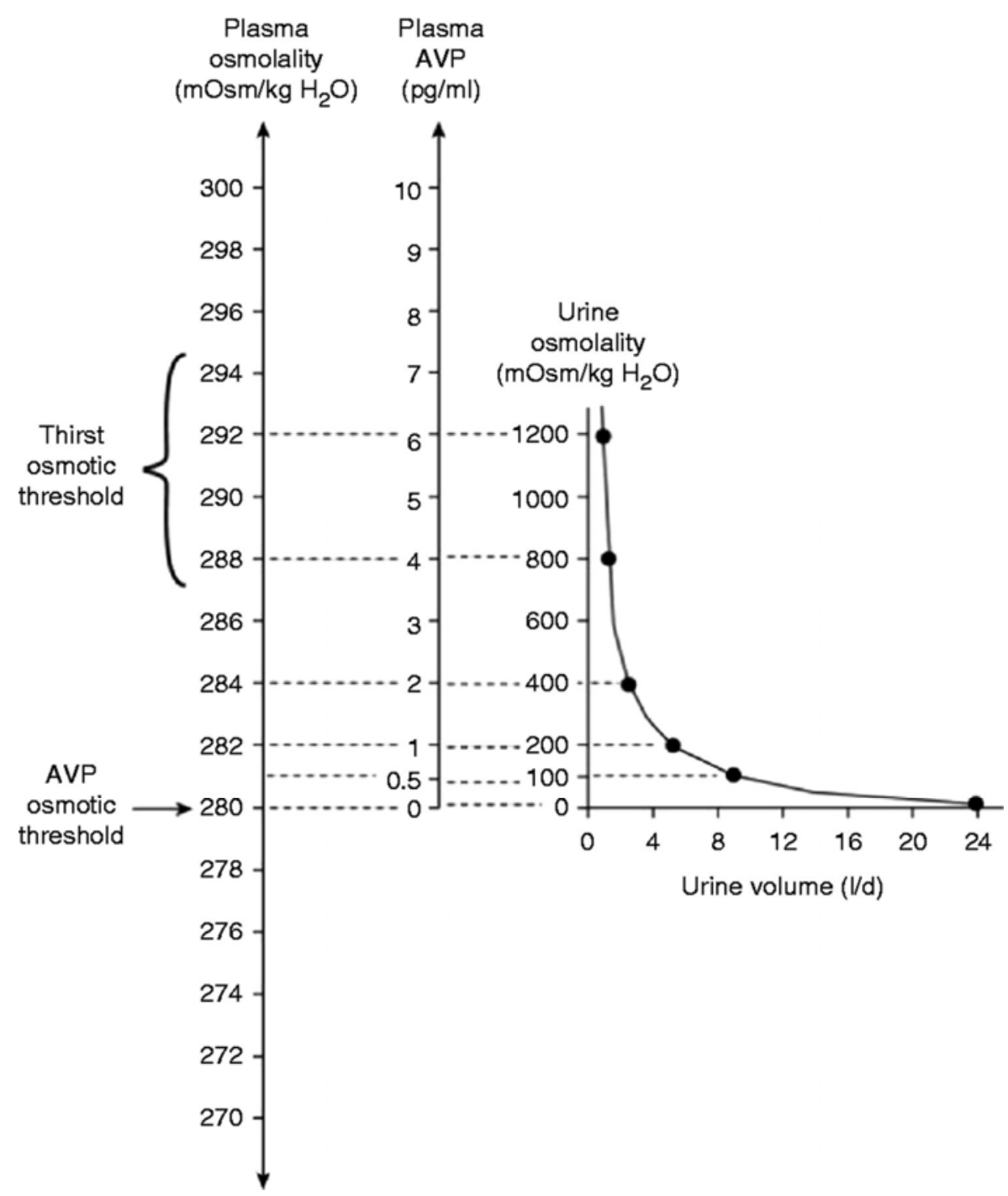

This article is protected by copyright. All rights reserved. 


\section{Figure 2:}

Maximum urinary osmolality after dehydration. Data from Miller et al. (26)

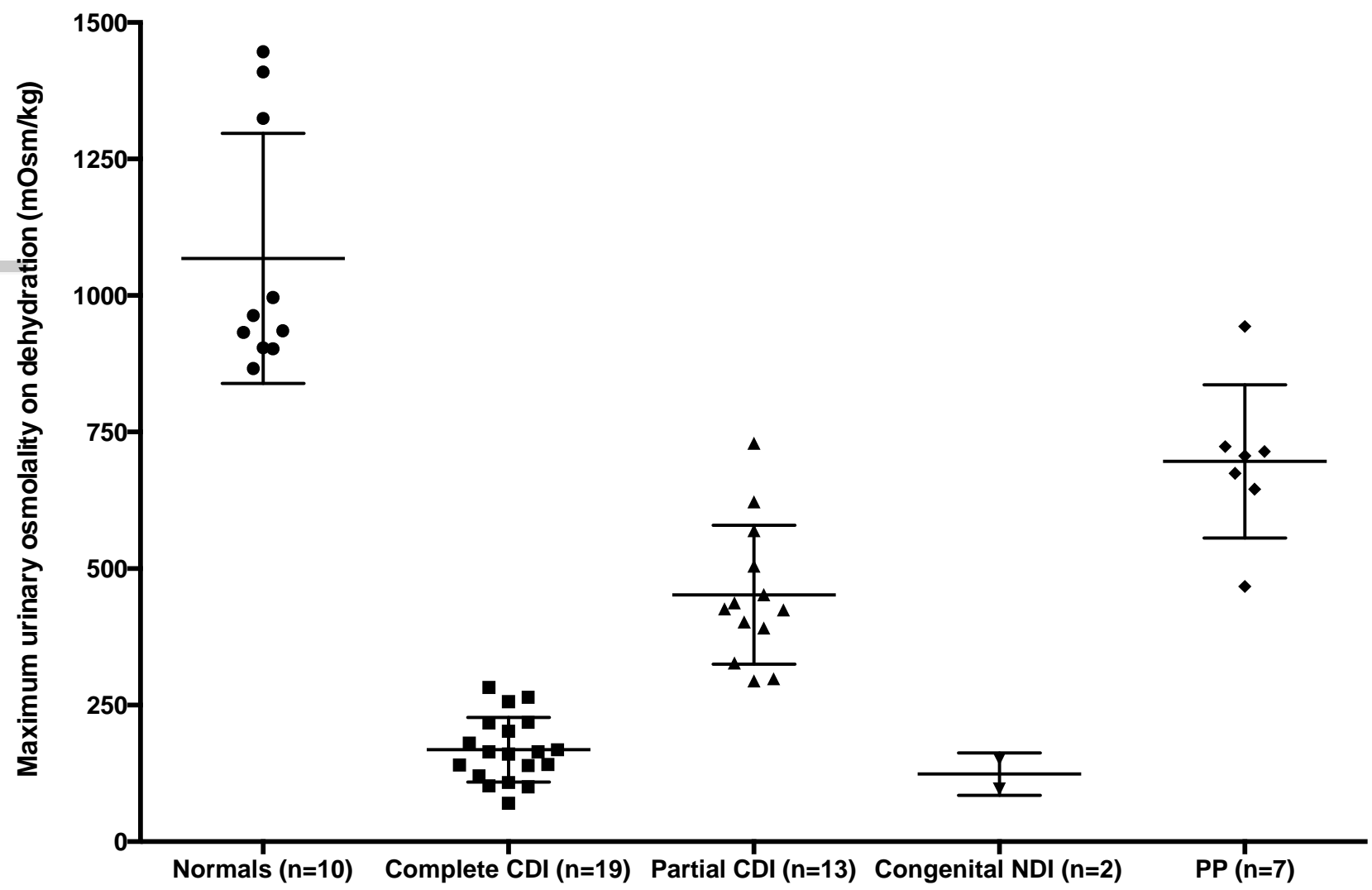

Whiskers represent median and interquartile ranges 


\section{Figure 3:}

Change in urinary osmolality after vasopressin injection. Data from Miller et al (26)

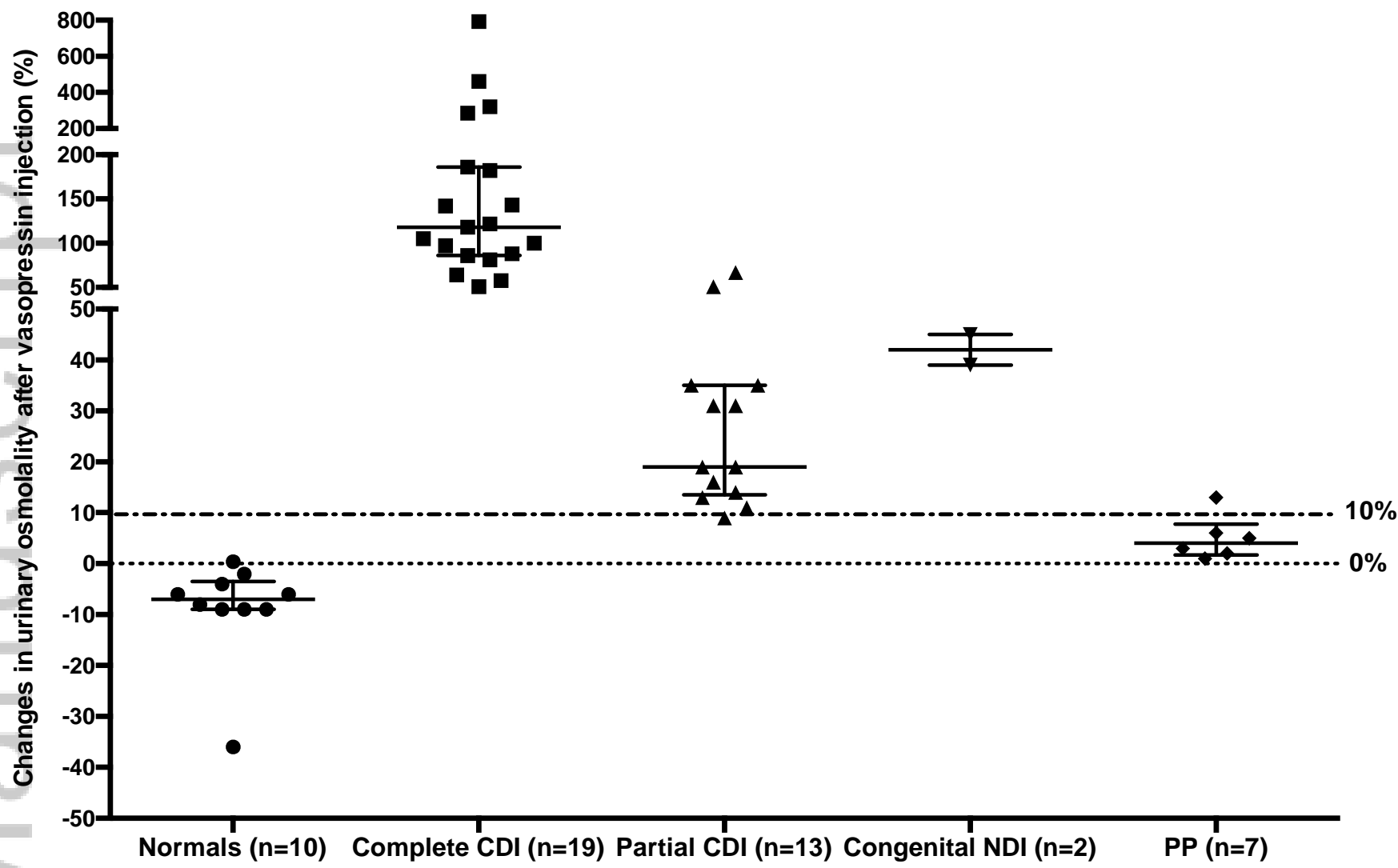

Whiskers represent median and interquartile ranges 


\begin{abstract}
The main determinants for the maintenance of water homeostasis are the hormone argininevasopressin (AVP) and thirst. Disturbances in these regulatory mechanisms can lead to the polyuria-polydipsia syndrome, which comprises of three different conditions: central diabetes insipidus (DI) due to insufficient secretion of AVP, nephrogenic DI caused by renal insensitivity to AVP action, and primary polydipsia due to excessive fluid intake and consequent physiologic suppression of AVP. It is crucial to determine the exact diagnosis because treatment strategies vary substantially.

To differentiate between the causes of the polyuria-polydipsia syndrome, a water deprivation test combined with desmopressin administration is the diagnostic "gold-standard". Thereby, AVP activity is indirectly evaluated with measurement of urine osmolality after prolonged dehydration. However, this test has several limitations and may fail to precisely distinguish between patients with primary polydipsia and mild forms of central and nephrogenic DI. The direct measurement of AVP during the water deprivation test, which was reported in the 1980s has not been widely adopted due to availability, assay issues and diagnostic performance. Recently, copeptin, the c-terminal portion of the larger precursor peptide of AVP, has been evaluated in the setting of the polyuria-polydipsia syndrome and appears be a useful candidate biomarker for the differential diagnosis. A standardised method for the water deprivation test is presented, as part of a joint initiative of the Endocrine Society of Australia, the Australasian Association of Clinical Biochemists and the Royal College of Pathologists of Australasia to harmonise dynamic endocrine tests across Australia.
\end{abstract}

\title{
Key words
}

Polyuria-polydipsia syndrome, diabetes insipidus, primary polydipsia, vasopressin, copeptin 


\section{Figure 4:}

Proposed diagnostic algorithm for the differential diagnosis of the polyuria-polydipsia syndrome

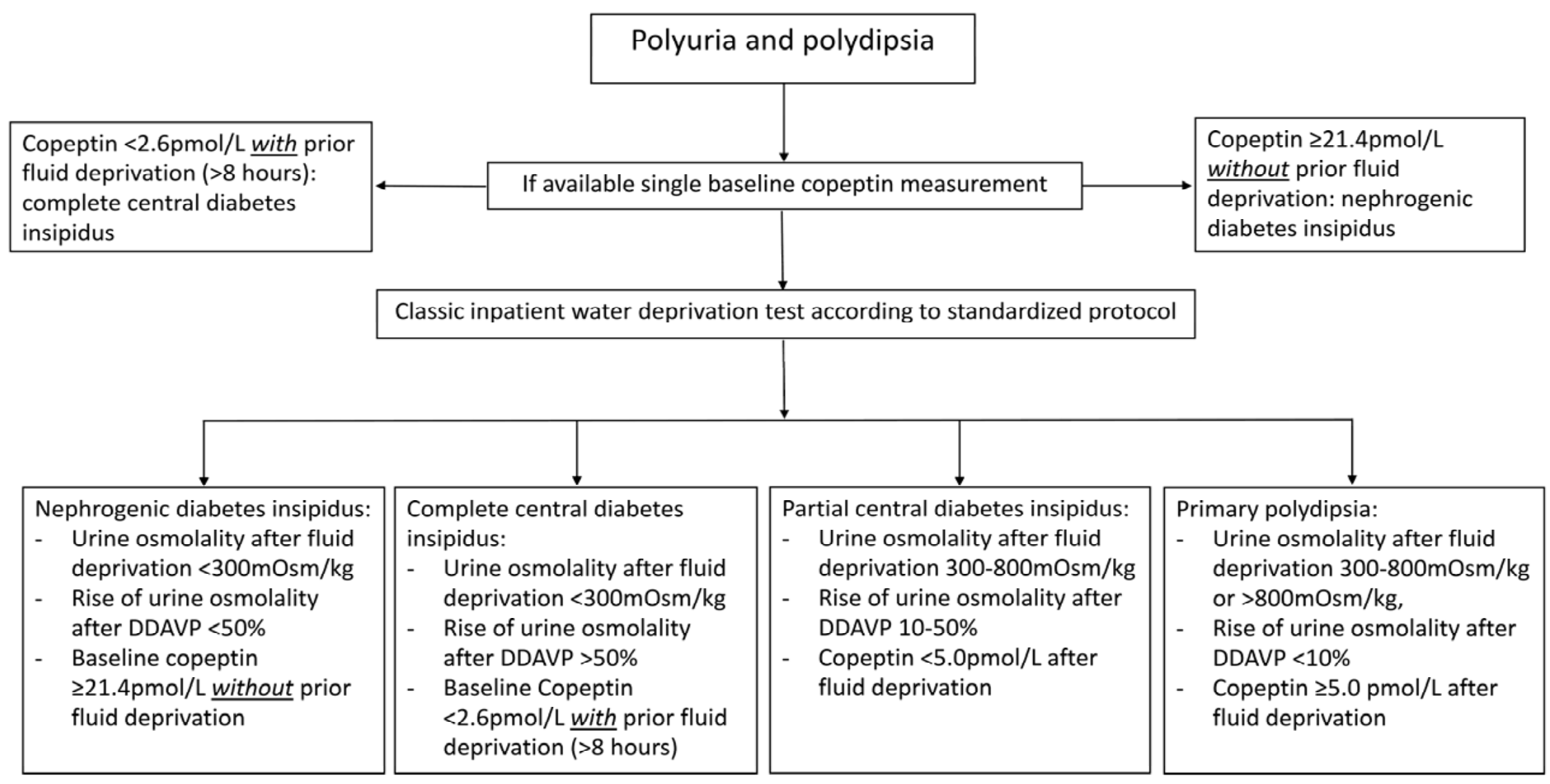

References: (29, 35, 38)

This article is protected by copyright. All rights reserved. 


\section{University Library}

\section{- M M I E R R V A gateway to Melbourne's research publications}

Minerva Access is the Institutional Repository of The University of Melbourne

Author/s:

Nigro, N;Grossmann, M;Chiang, C;Inder, WJ

Title:

Polyuria-polydipsia syndrome: a diagnostic challenge

Date:

2018-03-01

Citation:

Nigro, N., Grossmann, M., Chiang, C. \& Inder, W. J. (2018). Polyuria-polydipsia syndrome: a diagnostic challenge. INTERNAL MEDICINE JOURNAL, 48 (3), pp.244-253. https:// doi.org/10.1111/imj. 13627 .

Persistent Link:

http://hdl.handle.net/11343/283429 